\title{
Yield Gap Survey in Sudanno-Guinea Savanna Agro-Ecological Zones of Ghana
}

\author{
Baba I. Y. Inusah ${ }^{1}$, Wilson Dogbe ${ }^{1}$, Alhassan Lansah Abdulai ${ }^{1}$, Julius Yirzagla ${ }^{2}$, Michael Mawunya ${ }^{1} \&$ \\ Abu Safiyanu Issahak ${ }^{1}$ \\ ${ }^{1}$ CSIR-Savanna Agricultural Research Institute, Box 52, Nyankpala -Tamale, Ghana \\ ${ }^{2}$ CSIR-Savanna Agricultural Research Institute, Box 46, Manga - Bawku, Ghana \\ Correspondence: Baba I. Y. Inusah, CSIR-Savanna Agricultural Research Institute, Box 52, Nyankpala -Tamale, \\ Ghana. E-mail: iiybaba@yahoo.com
}

Received: August 18, 2014 Accepted: December 15, 2014 Online Published: January 16, 2015

doi:10.5539/sar.v4n1p127 URL: http://dx.doi.org/10.5539/sar.v4n1p127

\begin{abstract}
Yield gap survey (YGS) was carried out in nine selected communities in the Sudanno-Guinea Savannah (SGS) rice growing ecologies of Ghana in the 2012 and 2013 cropping seasons. One lead farmer was selected from each community to host researcher-managed fields. The specific objectives of the study were to determine the causes of yield gaps in rain fed and irrigated ecologies of the SGS of Ghana and to suggest ways by which the gaps can be bridged to enhance the production of the crop in Ghana

In both 2012 and 2013 seasons, farmers in the Sudan savannah zone recorded higher gaps in rice yields (average $55 \%$ ) than their compatriots in the Guinea Savannah (average 49\%). The analysis of data collected from YGS indicated that factors such as difficult weather and soil conditions, insufficient access to mechanization services/improper land preparation, lack of fertilizers, the use of unimproved rice seed, untimely field operations and inadequate water and pest (in particular weed) management, were some of the key factors that adversely influence rice yields in the study area.

Unrestricted access to mechanization services delivery, intensified use of improved rice seed, appropriate melioration with organic and inorganic fertilizers, together with robust soil and water management interventions are essential requirements for bridging experiment-based yield gaps for enhanced rice yields in the Sudanno-Guinea Savannah zones of Ghana.
\end{abstract}

Keywords: experiment-based yield gap, exploitable gaps, rice sector development hub

\section{Introduction}

Rice (Oryza sativa L.) is a major food and cash crop in Ghana today. The rice sector employs close to $20 \%$ of farming households with about $80 \%$ of national production being concentrated in the Sudanno-Guinea Savannah agro-ecological zones of Ghana (SRID, 2012; Boadu, 2012). The total annual demand for this commodity in Ghana is estimated at over 950,000 metric tons (SRID, 2012). The Ghana Minister for Food and Agriculture (MoFA), at a recent 'Meet-the-Press' meeting with newsmen in Accra, stated that the average annual rice import bill stood at US\$ 306 million with domestic production accounting for only 46\% of total supply and the shortfall of $56 \%$ being met by imports (GhanaWeb, 2014). Against this backdrop, rice acreage and yields are indicated to have remained stagnant in recent times. The variance between potential and the current rice yields obtained by farmers was investigated under the concept of yield gap analysis in this study.

\subsection{Concept of Yield Gap Analysis}

Yield gap is defined as the difference between maximum attainable yield and actual yield obtained by farmers. Maximum attainable yield refers to the highest yield that could be reached by a crop in a given environment (Evans \& Fischer, 1999) or estimates from crop models that assume perfect management and lack of yield-reducing factors or the highest yields at agricultural research stations or farmers' fields (Lobell et al., 2009).

Reported causes of yield gaps (Wopereis et al., 1999; Becker et al., 2003) include biophysical factors, socio-economic factors and institutional or political aspects Yield gaps may be categorised into: unexploitable 
gaps (cannot be narrowed or exploited and are due mainly to nontransferable factors or environmental conditions), less exploitable gaps (can be exploited but with little economic gain and are due mainly to the yield ceiling of crop varieties or law of diminishing returns in a production function) and exploitable (manageable) gaps due mainly to suboptimal crop management practices and can be bridged by deploying more efficient research and extension delivery.

Institutional or policy issues have to do with market price for rice, credit, input supply, land tenure, access to market, research and extension support which can be influenced in one way or the other by government policy direction. An interplay of biophysical, socio-economic and institutional dynamics influence rice production one way or the other. To solicit answers to causes of rice yield gap requires that we engage all stakeholders (farmers, researchers and other key actors in the rice value chain) at any given growing ecology. The goal of this study was to characterize rice production systems in the target areas and to quantify yield gaps. The specific objectives were to determine the causes of yield gaps in rain fed and irrigated rice growing ecologies of the Sudanno-Guinea Savannah agro-ecological zones of Ghana and to suggest ways by which the gaps can be bridged to enhance the production of this all important strategic crop in Ghana.

Farmer, experiment and model-based yield gap concepts are depicted in Figure 1. Maximum yields obtained in high yielding farmers' fields (Figure 1) seem an attainable target if the underlying causes of Farmer based yield gaps can be elucidated by way of YGS in the particular zone.

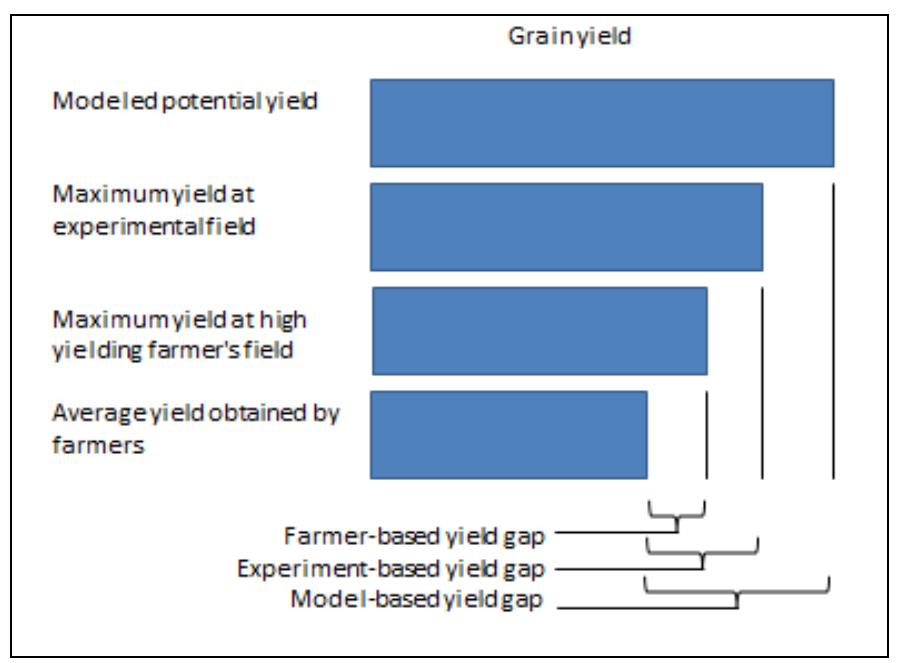

Figure 1. Farmer, Experiment and Model-based yield gaps

The genetic potential of a cultivar depends on the existence of a favourable environment which will enable the cultivar to express its full potential in terms of the desired product, in the case of rice it is the grain (De Datta, 1981). The environment comprises soil type, weather, nutrient, diseases and pests (including weeds) and any other factor that may prevent or enhance the expression of genetic yield potential during the season. Favourable environment permits effective use of inputs for yield improvement. Suitable management involves putting in place proven best practices in farming often referred to as good agronomic practices (GAP) to manipulate the environmental factors to obtain improved yield. GAP include use of improved high yielding seed, appropriate land preparation techniques, correct planting methods and appropriate soil, water and fertilizer management programmes together with pest $\&$ disease management schedules. Others are timely and appropriate harvesting and post harvest management of the crop/harvest (Duwari, 1998; Ofori et al., 2010). Efforts to bridge or narrow yield gaps should focus not only on increasing rice yield but also on reducing production costs via improvement in the efficiency with which production factors are utilized; and should involve dynamic technological developments in rice production, as the gaps tend to enlarge with improvement of the yield potential of rice varieties (Khush, 1995; Cromwell, 1996; Van Tran et al., 1999; Savary \& Castilla, 2009).

The General steps in yield gap analysis are show in Figure 2. On the whole the diagramme shows that from the mass of data gathered from a YGS it is imperative to identify and categorise constraints, determine their underlying factors (exploitable or not exploitable) in order to propose remedial policy and technological interventions. 


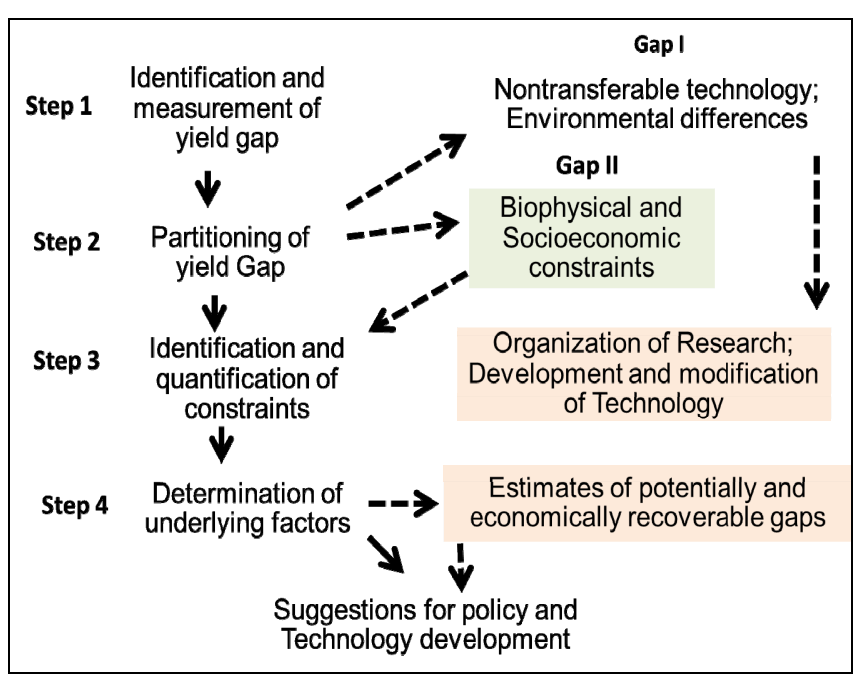

Figure 2. General steps in yield gap analysis (After Ajayi: AfricaRice)

A cursory look at the different production ecologies in Ghana (Table 1) indicates that there is a wide gap in rice yields that can be exploited to enhance rice production. This, together with expansion in area under cultivation could help boost overall production in the country. Factors that contribute to low yields need to be identified and analyzed through YGS carried out in the production ecologies.

Table 1. Rice yield under different production ecologies in Ghana

\begin{tabular}{cc}
\hline Production ecology & Rice yield $(\mathrm{t} / \mathrm{ha})$ \\
\hline Sawa technology $\times$ & 5.0 \\
Lowland rainfed $*$ & 2.5 \\
Upland rainfed $^{*}$ & 1.0 \\
Irrigated rice $^{*}$ & 4.6
\end{tabular}

*MoFA (2007); ×CSIR-Crops Research Institute (2007)/Ofori et al. (2010).

\section{Materials and Methods}

Characterization of rice production systems in target areas and assessment of yield gaps and their causes are the first steps in priority-setting for research and technology development. They require reliable agronomic/biophysical data collected from representative fields in the target area by field survey, socio-economic information collected by household survey and weather/meteorological data.

\subsection{Description of Study Area}

In the 2012 and 2013 rainy seasons Yield gap studies were conducted in ten communities in the Sudanno-Guinea savannah agro-ecological zones of northern Ghana. Specifically the survey fields were established in the Navrongo and Savelugu rice sector development hubs which are zones in northern Ghana where concentrated research and development activities are being carried out by the Council for Scientific and Industrial Research/Savanna Agricultural Research Institute (CSIR-SARI) together with its partners - the Africa Rice Center (AfricaRice), International Institute of Tropical Agriculture (IITA) and others under the Africa Rising-Feed the Future Programme. The Savelugu hub communities which were in the Savelugu and Tolon administrative Districts in the Northern Region (N/R) of Ghana included Boggu, Nabogu, Libga, Largbani, Tiborgnayili, Tingoli, Tibali, Manguli, Gbanjong and Cheyohi No. 2. Libga farmers operate from the developed Libga Irrigation Scheme. The Navrongo hub communities in the Kasena-Nankana District of Upper East Region (UE/R) of Ghana included Nyangua, Tampola, Kologo, Gongnia, Tekuru, Gia, Bonia and Samboligo. Gongnia and Gia farmers who were selected operate from the developed Tono Irrigation Scheme under the Irrigation 
Company of Upper Regions (ICOUR) Ltd. Communities in both hubs were selected at random following a Diagnostic survey conducted earlier by the research team.

\subsubsection{Sudan Savannah Zone (Kasena-Nankana District)}

The vegetation of the Kasena-Nankana municipality is of the Sudanno savannah type with grassland separating deciduous trees. It comprises open savannah with fire-swept grassland and deciduous trees. Some of the most densely vegetated parts can be found along river basins and forest reserves e.g. the Sissili and Asibelika river basins, Kologo and Naaga forest reserves. Common trees found are Neem (Azadiracta indica), dawadawa (Parkia biglobosa), baobab (Adansonia digitata), sheanut (Vitellaria paradoxa) and mango (Mangifera india). The climatic conditions are characterized by the dry and wet seasons, which are influenced mainly by two air masses - the North-East Trade winds and the South-Westerlies (Tropical Maritime).The Harmattan air mass (North-East Trade Winds) is usually dry and dusty as it originates from the Sahara Desert. Day temperatures are high recording $42^{\circ}$ Celsius (especially in February and March) and night temperatures are as low as $18{ }^{\circ} \mathrm{C}$. The SSZ experiences the tropical maritime air mass between May and October. This brings rainfall averaging 950 $\mathrm{mm}$ per annum. Generally, the soils in Sudan savannah zone of Ghana are developed over granites and stones. The topsoil's are light varying in texture from coarse sands to loams. The subsoils are also heavier varying from coarse sandy loams to clays with varying amount of gravel (Adu, 1969). The texture of the soils varies from loamy sand, sandy loam to loam with the $\mathrm{pH}$ ranging from 5.4 to 6.1 (Owusu-Bennoah et al., 1995). Majority of the soils in the Sudan savannah agro-ecological zone occupy gentle undulating to gently rolling topography yet are more vulnerable to erosion than those soils occurring on the more strongly rolling relief of forest zones in the southern part of Ghana. The soils of this SSZ have an extreme moisture regime relationship and have a generally lower nutrient status compared to the Guinea savannah zone. They have less organic matter accumulation with majority having less than $2 \%$ in the surface horizon owing to high temperatures resulting in rapid rate of decomposition (Adu, 1969). Phosphorus and nitrogen deficiencies are the major constraints to crop production of the soils in this area (Adu, 1969; Kanabo et al., 1978; Owusu-Bennoah \& Acquaye, 1989). Nitrogen in these parts is lost from the soil through leaching and denitrification (Arnon, 1975).

\subsubsection{Guinea Savannah Zone (Savelugu and Tolon Districts)}

The Savelugu and Tolon districts of N/R of Ghana have a mono modal rainfall pattern (May-October) with an annual mean of $1044 \mathrm{~mm}$ and mean daytime relative humidity of $54 \%$. Temperature generally fluctuates between 25 and $45{ }^{\circ} \mathrm{C}$ with a mean annual temperature of $28^{\circ} \mathrm{C}$. The vegetation is typically Guinea Savannah characterised by large areas of grassland interspersed with trees as in the SSZ. The soils in the zone are dominated by Savannah Ochrosols. They are moderately deep to deep and are generally developed over granites and stones. Decomposing rock or hard rock may be encountered within $150 \mathrm{~cm}$ depth. The topsoils are generally thin $(<20 \mathrm{~cm})$, greyish brown sandy loam, weak granular and friable. They are light, varying in texture from coarse sands to loams. Ironstone concretions and sandstone brashes of about $10-40 \%$ commonly occur in some of these soils. The subsoils are relatively heavy, varying from coarse sandy loams to clays with varying amounts of gravel. The sandy nature of the soil makes it suitable for the production of root and tuber crops and cereals such as maize. The Volta series $1 \& 2$ which occur along the fringes of the main river beds in the region are both silty clay loam, heavy textured soils with high moisture holding capacities. Both series in the zone are suitable for rice cultivation (Adu, 1995a, 1995b; Asiamah et al., 1996; FAO, 1988).

Field and household surveys were the means employed in this study for characterizing constraints to crop production in the individual farmer's field. The constraints included yield-limiting factors such as soil and water, yield-reducing factors such as pests (e.g. diseases, insects and weeds), crop management (fertilizer application, pest management, mechanization), and socio-economic factors (farmer's status, family size, household income, expenses and investment). We employed a Yield Gap Survey protocol (AfricaRice, 2011) in this study which provided guidelines for the selection of study fields, a set of field monitoring tools, and guidelines for data collection on crop management practices (IRRI, 2002) through interview. The protocol also dealt with follow-up surveys focusing on questions about farmers' views on constraints to rice production and crop management practices. It covered all crop management practices from land preparation to harvest (IRRI, 1996; AfricaRice, 2011). Implementing the protocol required a multidisciplinary research team composed of agronomists, weed scientists, crop protectionists and socio-economists.

Yield gap studies (YGS) in 2012 and 2013 were carried out in all participating communities in each zone. Eleven (11) farmers from each of the four communities were involved in the survey. A lead (eleventh) farmer was selected from each community to host researcher-managed plots. They were provided with agro inputs and technical backstopping by researchers from SARI and AEAs from MoFA. Each of the lead farmers was provided with 2 
bags $(100 \mathrm{~kg})$ of NPK $\mathrm{N}_{15-15-15}$ fertilizer, $1 \mathrm{bag}(50 \mathrm{~kg})$ of Sulphate of ammonia $\left(\mathrm{N}_{21}\right)$ and 2 litres of pre-emergence herbicide - Alligator (pendimethalin) to help maintain a 0.40 hectare rice field. Detailed assessment of agronomic and management practices used by rice farmers in the communities was undertaken. Prior to the establishment of the trials in a season, all participating farmers from both hubs were taken through training at workshops on YGS organized at Savelugu and Navrongo towns (Figure 4).

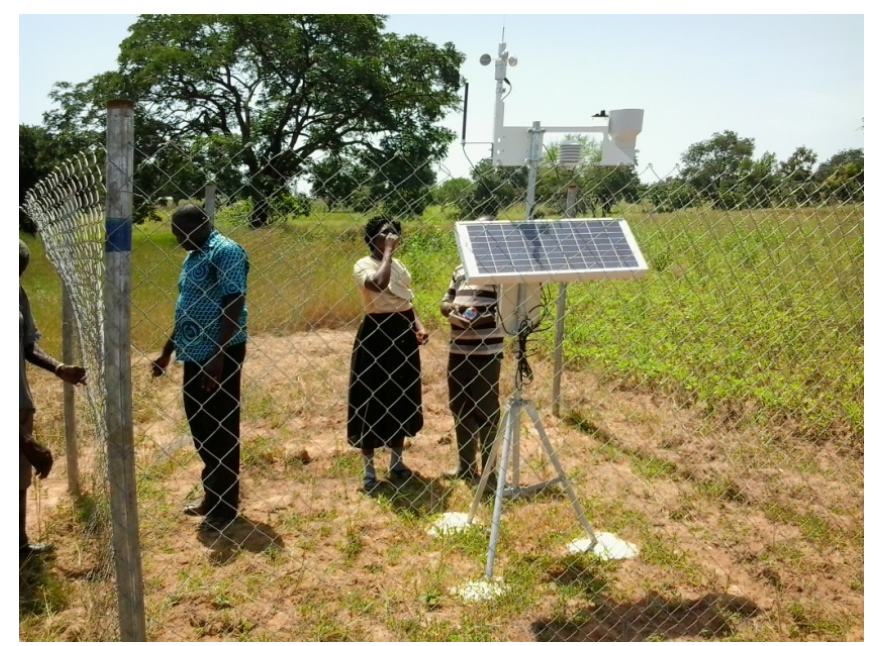

Figure 3. Some YGS researchers inspect the project's meteorological station at Nyangua community, Navrongo Hub

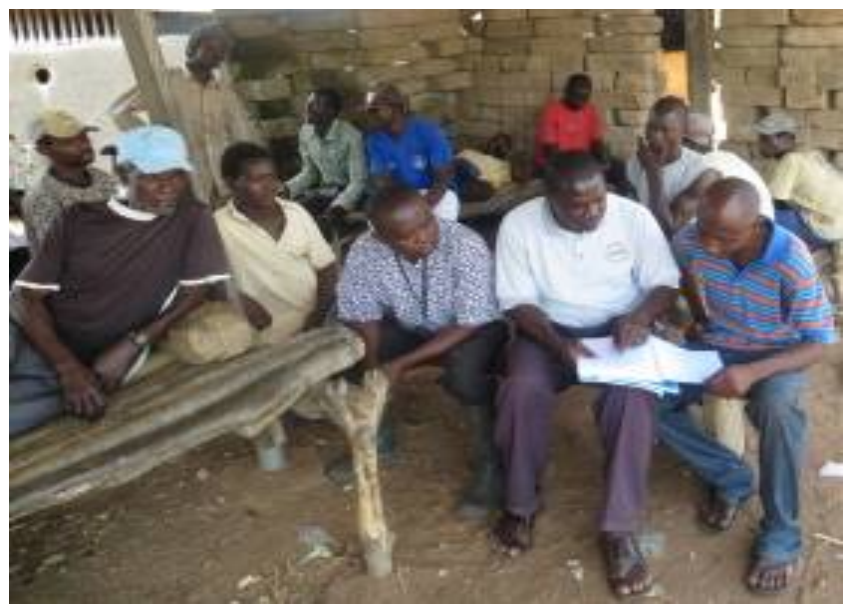

Figure 4. Backstopping MoFA AEAs \& lead farmers at Tampola, Navrongo Hub

\subsection{Field Survey and Data Collection}

On field, a $200 \mathrm{~m}^{2}$ area (survey plot) was measured from each participating farmer's 0.40 ha field and within this area, 3 yield plots were established diagonally across. Each yield plot had a dimension of $3 \mathrm{~m} \times 4 \mathrm{~m}$. In all the study sites, soil samples were taken from farms together with GPS locations of the sites and exact field size measurements.

Before starting the survey, a meteorological station was established at Nyangua in the Navrongo Hub (Figure 3) to ensure that weather data could be collected in the target area. Meteorological information in the Savelugu hub was easily accessible because of the existence of a regional station at the Tamale airport in the District. The minimum weather data set collected consisted of daily maximum and minimum temperatures, relative humidity, wind speed, direction and gust, atmospheric pressure and, solar radiation (or hours of sunshine). It is important to note that field observers did not give advice on crop management practices to farmers during this survey. This was to avoid farmers changing their own practices during the season. 


\section{Results and Discussion}

\subsection{Achievements}

Some of the outputs of the Yield Gap study included the following: Two research scientists from the CSIR-SARI and 15 MoFA AEAs were trained by Africa Rice Center to collect data with smart phones and Tablets; an automated weather station was established by Africa Rice Center in the Navrongo Hub to collect meteorological data; routine monitoring and data collection in the hubs were carried out; pre- and post-harvest data based on a standardized protocol for yield gap assessment was gathered; training at YGS workshops were organized, GPS locations of farms and sizes were documented, soil samples and basic data of farmers (bio-data, production systems (agro-eco-system), crop duration, varieties and establishment methods were gathered There were also follow-up focus group discussions in the communities with the farmers about rice production constraints.

\subsection{Farmers' Paddy Yields in 2012 Within the SSZ and the GSZ}

Grain yield (kg/ha) in 2012 across 7 communities in the Sudan and Guinea savannah agro-ecological zones of Ghana are presented in Figure 5 using Sigma plot programme (Systat Software Inc, 2012).

In 2012, in the Navrongo rice sector development hub in the Upper East Region (UER) of Ghana, the highest farmer managed plot yield was $5444 \mathrm{~kg} / \mathrm{ha}$ at Gongnia, while the highest researcher managed farmer's plot yield was $7750 \mathrm{~kg} / \mathrm{ha}$ at Kologo (Figure 5). The mean researcher assisted plot yield was 6000 whilst an overall farmer mean yield was $2692 \mathrm{~kg} / \mathrm{ha}$. The estimated mean yield gap in the hub in 2012 was thus $3300 \mathrm{~kg} / \mathrm{ha}$, which represents $55 \%$ of potential yield for the hub.

Yield gap analysis: Sudan Savanna zone of Ghana

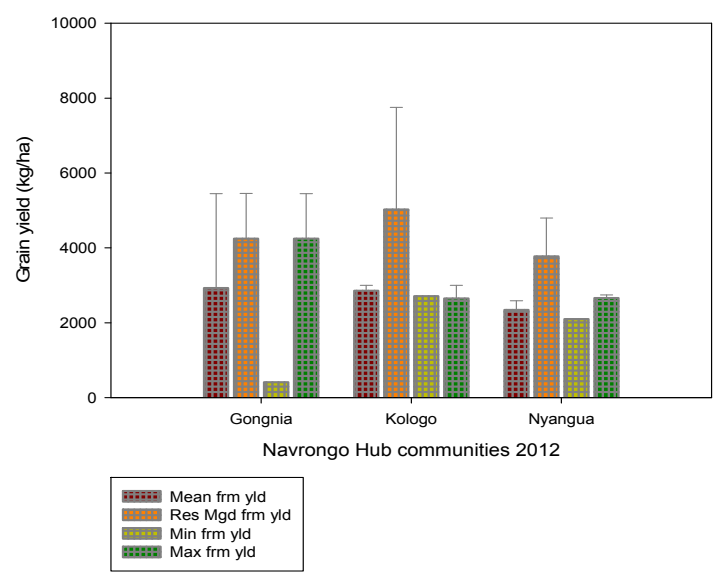

Yield gap analysis: Guinea Savanna zone of Ghana

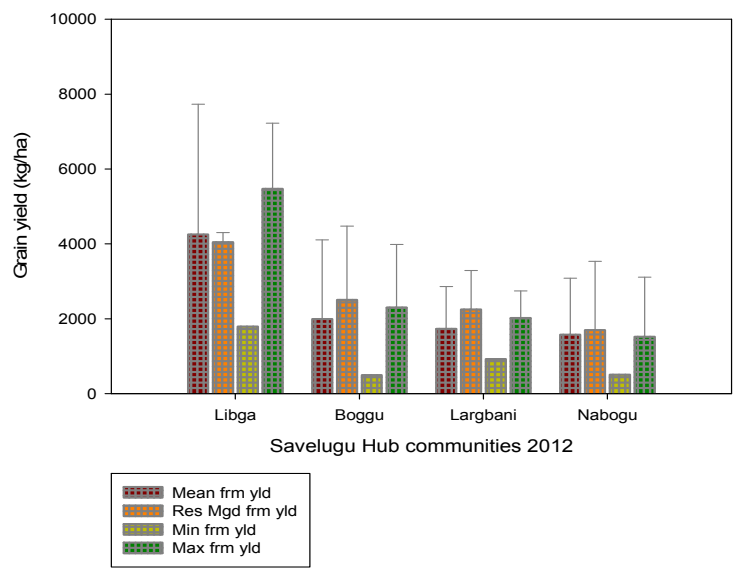

Figure 5. Grain yield (kg/ha) in 2012 across 7 communities in the Sudan and Guinea savanna agro-ecological zones of Ghana (Error bars indicate standard error)

In the same year, yield gap analysis in the Savelugu hub in the Northern Region (NR) of Ghana indicated that the highest farmer managed plot yield was $4227 \mathrm{~kg} / \mathrm{ha}$ obtained at Libga, compared to a lower $3865 \mathrm{~kg} / \mathrm{ha}$ researcher assisted farmer's plot yield at Libga. The highest researcher assisted farmer's plot yield in the hub was 3895 $\mathrm{kg} / \mathrm{ha}$ at Boggu (Figure 4). The mean researcher assisted plot yield was $3435 \mathrm{~kg} / \mathrm{ha}$ compared to an overall farmer plot average of $1811 \mathrm{~kg} / \mathrm{ha}$, giving an estimated yield gap of $1624 \mathrm{~kg} / \mathrm{ha}$ or $47 \%$ of potential yield.

\subsection{Farmers' Paddy Yields in 2013 Within the SSZ and the GSZ}

Grain yield (kg/ha) in 2013 across 9 communities in the Sudan and Guinea agro -ecological zones of Ghana are depicted in Figure 6 using Sigma plot programme (Systat Software Inc, 2012).

In 2013 in the Navrongo hub in the UE/R of Ghana, the highest farmer managed plot yield was $4000 \mathrm{~kg} / \mathrm{ha}$ at Bonia as against the highest researcher assisted farmer plot yield of $6600 \mathrm{~kg} / \mathrm{ha}$ also at Bonia (Figure 6). The estimated mean researcher assisted farmer plot yield for the zone was $5615 \mathrm{~kg} / \mathrm{ha}$ relative to the an overall mean farmer plot yield of $2598 \mathrm{~kg} / \mathrm{ha}$, providing a yield gap estimate of $3017 \mathrm{~kg} / \mathrm{ha}$ or $53 \%$ for the Sudan savannah zone in 2013. 
Yield gap analysis: Sudan Savanna zone of Ghana

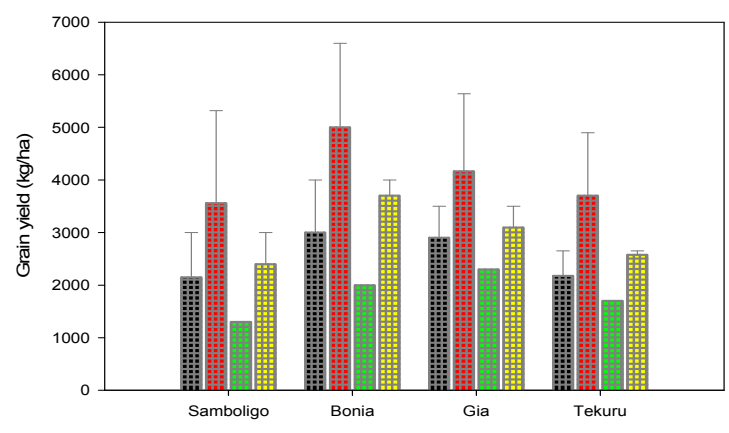

Navrongo Hub communities 2013
Yield gap anlysis: Guinea Savanna zone of Ghana
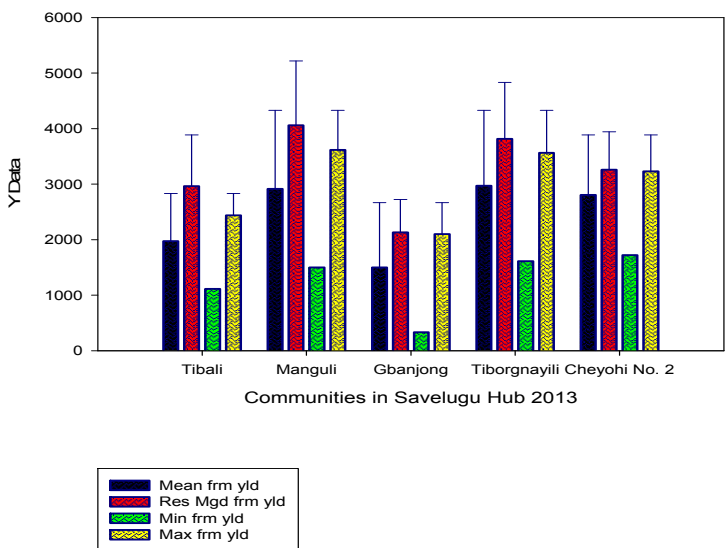

Figure 6. Grain yield (kg/ha) in 2013 across 9 communities in the Sudan and Guinea savanna agro-ecological zones of Ghana (Error bars indicate standard error)

Yield gap analysis in the Savelugu hub in the N/R of Ghana revealed that in 2013, the highest farmer managed plot yields were obtained at Manguli and Tiborgnayili, with both sites obtaining the same rice yield - $4332 \mathrm{~kg} / \mathrm{ha}$. The highest researcher assisted farmer plot yield was $5220 \mathrm{~kg} / \mathrm{ha}$, obtained at Manguli (Figure 6). The overall researcher assisted farmer plot mean yield was estimated at $4120 \mathrm{~kg} / \mathrm{ha}$, whereas the grand mean farmer managed plot yield for the zone was 2044, giving a rice yield gap for the Guinea savannah zone of $2077 \mathrm{~kg} / \mathrm{ha}$ or $50 \%$ of potential rice grain yield for the Guinea savannah zone in 2013.

In both 2012 and 2013 the Sudan savannah farmers recorded higher gaps in rice yields (average 55\%) than their compatriots in the Guinea Savannah zone (average 49\%).

Data collected on agronomic, physical, biophysical and management factors was useful in explaining the identified yield gaps and was used in further analysis. The study of this data indicated that apart from perennial adverse weather (unexploitable gap) and soil conditions, several other biophysical and socio-economic factors influence rice yields (Young, 1976; Duwari, 1998; FAO, 1999). Major sources of rice yield gaps based on interviews/observation in yield gap and diagnostic surveys across Sudanno-Guinea zones of Ghana are summarized in Table 2. Majority of farmers and extension workers from both zones when asked said that access to and inappropriate mechanical services (ploughing and harvesting), poor access and high cost of fertilizers together with inadequate farm management were the three topmost (very important) constraints to enhanced rice paddy yields in their areas. Respondents also underlined the use of farmer-saved (own) seeds, pest (particularly weed) management as important constraints to enhanced rice productions (Table 2).

In both years, remarkable variability in grain yields of rice was noticeable within and between the SSZ and the GSZ. With the exception of Kologo (SSZ), Manguli and Tiborgnayili (GSZ) the highest yields in both zones markedly, were from participants operating on the ICOUR Ltd. Irrigation Scheme at Tono (Bonia, Gongnia and Gia) and on the Libga Scheme. Rice farmers on these projects are generally more adept in terms of improved water management (bunding \& land leveling is almost second nature to them) and they occasionally relied on supplementary irrigation in periods of intermittent drought. The annual rainfall regime in the GSZ (1035 $\mathrm{mm})$ is much higher than in the SSZ $(950 \mathrm{~mm})$ and in most parts of the world water availability is synonymous with rice production (Gleick, 1993). The SSZ is also much hotter and drier (NAES, 1993). The lowlands soils for rice cultivation in GSZ are generally characterised by the Volta series 1 \& 2 which are silty, clay loam, heavy textured soils with high moisture holding capacities considered to be very suitable for rice cultivation. In comparison, the soils in SSZ are coarse sands to loams developed over granites and stones with an extreme moisture regime relationship and have a generally lower nutrient status compared to the Guinea savannah zone. They have less organic matter accumulation with majority having less than $2 \%$ in the surface horizon (Brammer, 1962; Vine, 1966; Owusu-Bennoah et al., 1995). In the balance, SSZ soils may be thought to be less endowed for crop production than those of the GSZ. Against this backdrop, the GSZ would therefore appear to be a relatively more favourable eco-system for rain fed rice production. 
Table 2. Major sources of rice yield gaps based on interview/observation in yield gap and diagnostic surveys across Sudanno-Guinea zones of Ghana

\begin{tabular}{lcl}
\hline $\begin{array}{l}\text { Sources of rice yield gaps } \\
\text { (topmost rice yield constraints) }\end{array}$ & $\begin{array}{l}\text { Score of } \\
\text { constraint* }\end{array}$ & $\begin{array}{l}\text { Proposals by respondents on how to remedy } \\
\text { problem }\end{array}$ \\
\hline Erratic and insufficient rainfall. & 7 & $\begin{array}{l}\text { Timely planting, use of early to medium maturing } \\
\text { varieties }\end{array}$ \\
$\begin{array}{l}\text { Untimeliness of cultural } \\
\text { operations }\end{array}$ & 7 & $\begin{array}{l}\text { Improved access to mechanization equipment e.g. } \\
\text { access to pool mechanization services of SADA and } \\
\text { ABCs }\end{array}$ \\
$\begin{array}{l}\text { Inappropriate land preparation } \\
\text { Improved access to mechanization equipment e.g. } \\
\text { Access to pool mechanization services of SADA and } \\
\text { ABCs } \\
\text { Certified rice seed dealers need to improve quality of } \\
\text { product they offer for sale; community seed production } \\
\text { need to be mainstreamed by MoFA } \\
\text { Improve access to quality extension delivery }\end{array}$ \\
$\begin{array}{l}\text { Use of uncertified (farmers own) } \\
\text { seed }\end{array}$ & 7 & 9
\end{tabular}

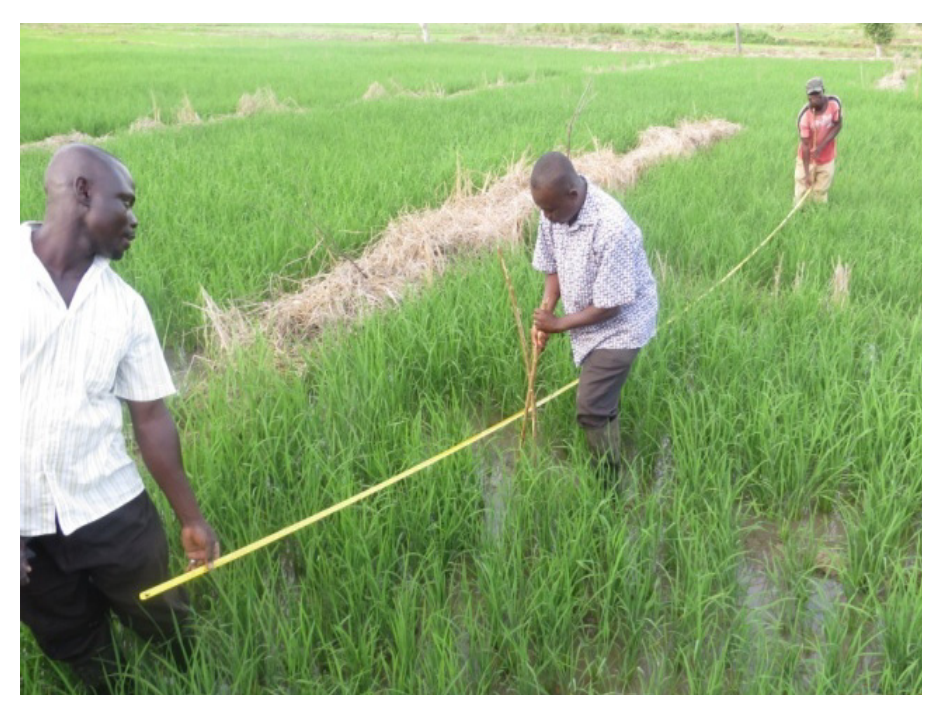

Figure 7. Establishing yield plots at Gongnia, Navrongo Hub

\section{Conclusion}

In both 2012 and 2013 cropping seasons, the Sudan savannah farmers recorded higher gaps in rice yields (average 55\%) than their compatriots in the Guinea Savannah zone (average 49\%). Intensified implementation of Good Agronomic Practices - viz; use of improved rice seed, appropriate melioration with organic and inorganic fertilizers, together with robust soil, water and pest management interventions are crucial inputs important in bridging experiment-based yield gaps for enhanced rice yields in the savannah zones of northern Ghana. 


\section{Acknowledgements}

The authors wish to acknowledge the CSIR-SARI, Africa Rice Center, International Institute of Tropical Agriculture (IITA) and the USAID funded Sustainable intensification of key farming systems in the Sudano-Sahelian Savannah of West Africa Project for providing the support for this work. We also commend CSIR-SARI Research Assistants Mr. Safiyanu Abu and Ms. Benedicta Atosona together with Ghana Ministry of Food and Agriculture (MoFA) Directors and Agricultural Extension Agents (AEAs) in the Kasena-Nankana and Savelugu Districts who worked tirelessly for the success of this study.

\section{References}

Adu, S. V. (1969). Soils of the Navrongo-Bawku area, Upper Region, Ghana. Memoir Number 5. Soil Research Institute, Kumasi, Ghana.

Adu, S. V. (1995a). Soils of the Bole-Bamboi area, Northern Region, Ghana. Memoir Number 14. Soil Research Institute, Kumasi, Ghana.

Adu, S. V. (1995b). Soils of the Nasia Basin, Northern Region, Ghana. Memoir Number 11. Soil Research Institute, Kumasi, Ghana.

Africa Rice Center (AfricaRice). (2011). Yield Gap Protocol 2011. Africa Rice Center, 01 BP. 2031, Cotonou, Benin.

Arnon, D. I. (1975). Mineral Nutrition of Maize. International Potash Institute, Bern/Switzerland. pp. 30, 100, 113-121.

Asiamah, R. D., Senayah, J. K., \& Adjei-Gyapong, T. (1996). Ethno-pedoligical surveys in the semi-arid savannah zone of northern Ghana. An ILEIA initiated project. Soil Research Institute Technical Report No. 185 , Kumasi, Ghana.

Becker, M., Johnson, D. E., Woperis, M. S. C., \& Sow, A. (2003). Rice yield gaps in irrigated systems along an agro-ecological gradient in West Africa. Journal of Plant Nutrition \& Soil Science, 166, 61-67. http://dx.doi.org/10.1002/jpln.200390013

Boadu, V. A. (2012). Rice price trends in Ghana (2006 -2011). USAID - GHANA. Monitoring, evaluation and technical support services. Ghana research and issue paper series, No. 02.

Brammer, H. (1962). Soils. In J. B. Wills (Ed.), Agriculture and Landuse in Ghana (pp. 88-126). London, Accra, New York: Oxford University Press.

Council for Scientific \& Industrial Research - Savannah Agricultural Research Institute (CSIR-SARI). (2012). Annual Report (pp. 56-66). Accra, Ghana.

Cromwell, A. (1996). Governments, farmers and seeds in a changing Africa. (p. 174), Wallingford, UK: CAB International.

De Datta, S. K. (1981). Principles and Practices of Rice Production (pp. 89-145). John Wiley and Sons Ltd.

Duwari, M., Tran, D. V., \& Nguyen, V. N. (1998). Reflections on yield gaps in rice production: how to narrow the gaps. International Rice Commission, 98/7-12, Cairo, (p. 21), Egypt.

Evans, L. T., \& Fischer, R. A. (1999). Yield potential: Its definition, measurement, and significance. Crop Science, 39, 1544-1551. http://dx.doi.org/10.2135/cropsci1999.3961544x

F.A.O. (1999). Expert Consultation on Bridging the Rice Yield Gap in the Asia-Pacific Region, FAO-RAP Publication No. 1999/41. (p. 30), Bangkok, Thailand.

F.A.O. (1988). F.A.O./Unesco Soil Map of the World Revised legend, with corrections. World Soil Resources Report 60. Rome. (Reprinted as Technical Paper 20, ISRIC, Wageningen, 1994).

GhanaWeb. (2014). Ghana takes steps to increase local rice production. Business News: Thursday, $24^{\text {th }}$ April, 2014. Accra, Ghana. Retrieved from www.ghanaweb.com/GhanaHomePage/business/artikel.php?

Gleick, P. H. (1993). Water in crisis: a guide to the world's fresh water resources. New York, Oxford University Press.

International Rice Research Institute (IRRI). (1996). Listening to the farmers (p. 93) Los Baños, the Philippines.

International Rice Research Institute (IRRI). (2002). Standard Evaluation Systems for Rice. Los Baños, Philippines. 
Kanabo, I. A. K., Halm A. T., \& Obeng, H. B. (1978). Phosphorus adsorption by surface samples of five iron pan soils of Ghana. Geoderma, 20, 299-306. http://dx.doi.org/10.1016/0016-7061(78)90018-6

Khush, G. S. (1995). Modern varieties - their real contribution to food supply and equity. Geojournal, 35(3), 275-284. http://dx.doi.org/10.1007/BF00989135

Lobell, D., Bala, G., Mirin, A., Phillips T., Maxwell, R., \& Rotman, D. (2009). Regional differences in the influence of irrigation on climate. Journal of Climate, 22(8), 2248-2255. http://dx.doi.org/10.1175/2008JCLI2703.1

NAES. (1993). Report 9. Farm Household Systems in Northern Ghana. Edited by Artur Runge-Metzeger and Lothar Diehl. Research Approach at the Nyankpala Agricultural Research Station (NAES). (G. Schimidt \& H. Mercer-Quarshie). Verlag Josef Margraf, Hohenloher, Str no. 2, Weikersheim, Germay. 3-8, 36-38.

Ofori, E., Kyei-Baffour, N., Mensah, E., \& Agyare, W. A. (2010). Yield Gap analysis in rice production from stakeholders' perspective at Annum valley bottom irrigation Project at Nobewam in Ghana. ARPN Journal of Agriculture \& Biological Sciences, 5, 6.

Owusu-Bennoah, E., Ampofo, J. G., \& Acquaye D. K. (1995). Phosphorus status of some semi-arid agricultural soils of northern Ghana. Ghana Journal of agricultural Science, 28-29, 29-35.

Savary, S., \& Castilla, N. P. (2009). A Survey Portfolio to Characterize Yield-reducing Factors in Rice. International Rice Research Institute, Los Baños, Philippines

Statistics, Research and Information Division (SRID). (2012). Agriculture in Ghana: Facts and figures. Ministry of Food and Agriculture (MoFA), Accra, Ghana.

Systat Software Inc. (2012). SigmaPlot Programme 12.5. Scientific Data Management Company. San Jose, California, USA.

Van Tran, D., Evans, L. T., \& Fischer, R. A. (1999). Yield potential: Its definition, measurement, and significance. Crop Science, 39, 1544-1551. http://dx.doi.org/10.2135/cropsci1999.3961544x

Vine, H. (1966). Tropical soils.. In C. C. Webster \& P. N. Wilson (1st ed.) (Eds.), Agriculture in the Tropics Longmans, London, UK.

Woperis, M. C. S., Donovan, C., Nebie, B., Guindo, D., \& N’Diaye, M. K. (1999). Soil fertility management in irrigated rice systems in Sahel and Savannah regions of West Africa.Part 1. Agronomic analysis. Field Crops Research, 61, 124-125.

Young, A. (1976). Tropical soils and soil survey. Cambridge. UK.: Cambridge University Press. 


\section{Appendix}

Appendix 1. Partner Institutions

\begin{tabular}{|c|c|}
\hline Partner & Role \\
\hline $\begin{array}{l}\text { Africa Rice Center } \\
\text { (AfricaRice) }\end{array}$ & $\begin{array}{l}\text { Project coordination, backstopping for multi-stakeholder platform establishment, } \\
\text { rice sector development hubs establishment, training of trainers, monitoring and } \\
\text { evaluation. }\end{array}$ \\
\hline $\mathrm{ABCs}$ & $\begin{array}{l}\text { Agricultural Business Centers-Private-Public- Partnership arrangement; one stop } \\
\text { shops for agro- inputs, mechanization and extension services and temporal storage } \\
\text { and milling of rice paddy (set up under Millennium Challenge Account Ghana } \\
\text { Compact - I) }\end{array}$ \\
\hline $\begin{array}{l}\text { International Institute of } \\
\text { Tropical } \quad \text { Agriculture } \\
\text { (IITA) }\end{array}$ & Project coordination \\
\hline $\begin{array}{l}\text { CSIR-Savanna } \\
\text { Agricultural Research } \\
\text { Institute }\end{array}$ & $\begin{array}{l}\text { Project implementation and coordination, facilitating multi-stakeholder platform } \\
\text { establishment, rice sector development hubs establishment, training of farmers } \\
\text { and other stakeholders, monitoring and evaluation. }\end{array}$ \\
\hline $\begin{array}{l}\text { CSIR-Crops Research } \\
\text { Institute }\end{array}$ & Exchange of experiences in Yield Gap Assessment and hub related activities \\
\hline $\begin{array}{l}\text { Ministry of Food and } \\
\text { Agriculture (MoFA) }\end{array}$ & $\begin{array}{l}\text { Establish and operate rice sector development hubs with the assistance of } \\
\text { Agricultural Extension Agents (AEAs) in the Navrongo and Savelugu rice sector } \\
\text { development hubs. }\end{array}$ \\
\hline $\begin{array}{l}\text { Irrigation Company of } \\
\text { Upper } \\
\text { (ICOUR) Ltd }\end{array}$ & $\begin{array}{l}\text { Management of irrigation facility at the Navrongo hub and provision of land } \\
\text { cultivation services and extension to irrigation farmers. }\end{array}$ \\
\hline $\begin{array}{l}\text { CSIR-Crops Research } \\
\text { Institute }\end{array}$ & Exchange of experiences in Yield Gap Assessment and hub related activities \\
\hline
\end{tabular}

Appendix 2. List of Abbreviations

AGRA - Alliance for Green Revolution in Africa

CSIR-SARI - Council for Scientific and Industrial Research Savanna Agricultural Research Institute

JICA - Japan International Cooperation Agency

MoFA-Ministry of Food and Agriculture

NRGP - Northern Rural Growth Progrmme

SADA - Savanna Accelerated Development Authority

USAID - United States Agency for International Development

\section{Copyrights}

Copyright for this article is retained by the author(s), with first publication rights granted to the journal.

This is an open-access article distributed under the terms and conditions of the Creative Commons Attribution license (http://creativecommons.org/licenses/by/3.0/). 